\title{
PKM Peningkatan Kualitas Sumber Daya Manusia melalui Pelatihan Keterampilan Komputer dan Administrasi Perkantoran di Madrasah Aliyah Islamiyah Syafi'iyah Sumberanyar Paiton Probolinggo
}

Ahmad Hudawi ${ }^{1}$, Ainur Rasit ${ }^{2}$, Alfain Hidayat ${ }^{3}$, Alfan WAnzilur Rahman ${ }^{4}$, Andika Miftahul Hasan ${ }^{5}$, Ridho Illahi Putra ${ }^{6}$,

Fakultas Teknik Jurusan Informatika Universitas Nurul Jadid

\{ahmad.hudawi@unuja.ac.id ${ }^{1}$, Ainur.rasit23@gmail.com², Alfainhidayat@gmail.com³, alfanwanzilurrahman@gmail.com ${ }^{4}$, andikeliyanto@gmail.com ${ }^{5}$, ridhoillahiputra2@gmail.com $\left.{ }^{6}\right\}$

\section{Submission: 18/09/2021 Received: 31/12/2021 Published: 31/12/2021}

Keywords:

MS Office, administration
Katakunci:

MS Ofiice,

Administrasi Perkantoran,
Abstract. This Community Service is a follow-up to research on Training to Improve the Quality of Human Resources and Computer Skills and Administration of Office Documentation. Educating the next generation through quality education is a state duty that must receive full support from the community. The education system will run well if it is supported by good human resources. Madrasah Aliyah Islamiyah Syafi'iyah Sumberanyar Paiton Probolinggo Syafi'iyah Sumberanyar Paiton Probolinggo This institution is engaged in the world of education and has problems in improving its human resources capabilities, especially in the field of administration and document archiving. Weak administration and archiving often causes problems, such as student data, grades, missing letters. Realizing this, the lecturers and students have the initiative to provide training to improve human resource capabilities. The training provided is in the form of MS Word, Excel, and office administration training. This training is expected to improve the ability of staff in managing schools, because through MS Word training, Excel staff are trained to archive data on grades, questions, letters, and financial reports into files and folders so that they can be arranged according to the time of creation. Meanwhile, office administration training can improve the ability of teachers and staff in drafting decision letters, mail expeditions, and others. The results of the service will be made in the form of a report and will be published in the National Service Journal.

Abstrak. Pengabdian kepada Masyarakat tersebut merupakan tindakn lanjut dari peneiitian tentang Pelatihan Peningkatan Kualitas Sumber Daya Manusia serta Keterampilan Komputer serta Administrasi Dokumentasi Perkantoran, Mencerdaskan generasi penerus melalui pendidikan yang berkualitas merupakan tugas negara yang harus mendapat dukungan penuh dari masyarakat. Sistem pendidikan akan berjalan dengan baik apabila didukung dengan sumberdaya manusia yang baik pula. Madrasah Aliyah Islamiyah Syafi'iyah Sumberanyar Paiton Probolinggo yang bergerak dalam dunia pendidikan 
mempunyai permasalahan dalam meningkatkan kemampuan SDM nya, khususnya di bidang pengadministrasian dan pengarsipan dokumen. Lemahnya pengadministrasian dan pengarsipan ini sering menimbulkan permasalahan, seperti misalnya data siswa, nilai, suratsurat yang hilang. Menyadari hal tersebut maka Dosen bersama mahasiswa punya inisiatif untuk memberikan pelatihan untuk peningkatan kemampuan SDM. Pelatihan yang diberikan berupa pelatihan MS Word, Excel, dan administrasi perkantoran. Pelatihan ini diharapkan dapat meningkatkan kemampuan staf dalam mengelola sekolah, karena melalui pelatihan MS Word, Excel staf dilatih untuk membuat arsip data nilai, soal, surat-surat, dan laporan keuangan ke dalam bentuk file dan folder agar dapat tersusun berdasarkan waktu pembuatan. Sedangkan pelatihan administrasi perkantoran dapat meningkatkan kemampuan guru dan staf dalam membuat draft surat keputusan, ekspedisi surat, dan lain-lain. Hasil pengabdian akan dibuat dalam bentuk laporan dan akan dipublikasikan dalam jurnal pengabdian Nasional.

\section{Pendahuluan}

Perkembangan teknologi informasi dan komunikasi telah berpengaruh terhadap berbagai aspek kehidupan manusia. Pergeseran paradigma ini tentunya menuntut kompetensi sumber daya manusia yang unggul di bidang teknologi informasi, aplikasi perkantoran seperti Microsoft Word dan Excel sudah dipastikan digunakan dalam mendukung semua pekerjaan administratif. Konsekuensinya, manusia dituntut pula memiliki kemampuan menganalisis suatu kasus atau berpikir logis. Fenomena yang terjadi di era revolusi industri 4.0 adalah kedudukan manusia yang akan digantikan oleh teknologi atau mesin apabila manusia tidak mampu menguasai teknologi tersebut (Permatasari \& lis Nawati, 2018).

Kondisi ini menuntut logika berpikir manusia harus lebih tinggi daripada teknologi tersebut. Tidak heran dewasa ini pekerjaan teknis atau pelaksana rutin tergantikan oleh mesin yang pada akhirnya terjadi pemutusan hubungan kerja atau PHK.

Peningkatan kualitas sumber daya manusia menjadi kebutuhan yang mendesak dalam menghadapi persaingan kerja yang semakin ketat, untuk itu maka diperlukan usaha yang maksimal dan susnguh-sunguh dari berbagai pihak. Upaya pemerintah melalui pelatihan untuk meningkatkan keterampilan dengan peningkatan kualitas SDM wajib dimiliki lulusan sekolah menengah atas khususnya Madrasah Aliyah Islamiyah Syafi'iyah 
Sumberanyar Paiton Probolinggo melalui pelatihan dalam meningkatkan keterampilan diberbagai bidang.

Peningkatan ketrampilan dan kualitas SDM juga diberikan kepada seluruh Iulusan MA Islamiyah Syafi'iyah, melalui peningkatan kualitas SDM diharapkan dapat meningkatkan kemampuannya agar kelak dapat membina sekolah secara mandiri. Masalah yang dihadapi oleh sekolah adalah keterbatasan kurang dapat mengembangkan oleh kemampuannya. Penguasaan tentang komputer khususnya Ms Word dan Excel diharapkan mereka mampu membuat surat menyurat dan pengarsipan dengan baik, Peningkatan kualitas SDM yang dimulai sejak dini dapat berpengaruh pada daya saing individu itu sendiri. Langkah yang di ambil adalah memberikan ketrampilan tambahan kepada mereka yang berusia produktif (Aribowo \& Endi Permat, 2017).

Salah satu ketrampilan yang akan diberikan kepada staf dan lulusan Madrasah Aliyah Islamiyah Syafi'iyah Sumberanyar Paiton Probolinggo adalah ketrampilan komputer adalah kebutuhan tentang penguasaan komputer, selain siswa kelas akhir juga mempunyai keinginan untuk membekali guru dan stafnya dengan ilmu administrasi perkantoran. Permasalahan yang dialami mitra adalah rendahnya kemampuan guru dan staf dalam mengelola data-data penting, seperti data tentang siswa, nilai, laporan keuangan, surat menyurat dan lain-lain. Sehingga tercapai kemampuan guru dan staf dalam peningkatan SDMnya dengan memahmi pelayanan administrasi perkantoran serta mendokumentasikan semua berkas dengan benar (PRATAMA, 2019).

\section{Metode}

Pelaksanaan pengabdian masyarakat ini dilaksanakan pada Bulan April 2021 di Madrasah Aliyah Islamiyah Syafi'iyah Sumberanyar Paiton Probolinggo, dimana dosen dan mahasiswa berkolaborasi terlibat bersama memberikan pengetahuan pelatihan pemahaman MS Office dan dokumentasi berkas dengan benar, adapun peserta yang terlibat Guru, TU serta siswa kelas akhir Madrasah Aliyah Islamiyah Syafi'iyah Sumberanyar Paiton (Arsana \& Dewa Ayu Putri Wulandari). Hal ini dilakukan agar pelaksanaan pengabdian masyarakat ini dapat dilaksaksanakan dengan baik 
dan terstruktur. Sehabis dilaksanakannya pelatihan MS Word, MS Excel serta administrasi perkantoran ini, partisipan pelatihan memiliki pengetahuan dan keterampilan dalam mempersiapkan serta membikin dokumen mulai dari mengetik hingga mencetak (print-out) dokumen secara mandiri, dan melakukan kegiatan tata administrasi serta pengarsipan surat secara baik, serta dapat mempersiapkan bahan presentasi secara sederhana dan mandiri (Pradana \& Dwi Achadiani, 2020).

Prosedur yang dilakukan dalam pengabdian ini dalah sebagai berikut :

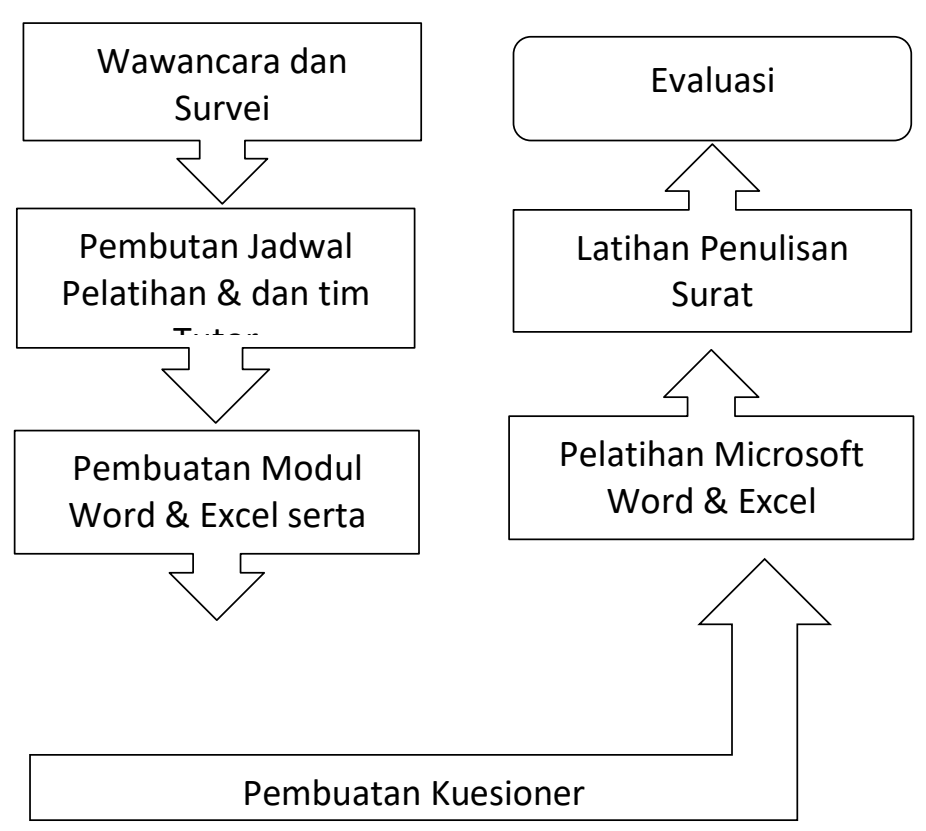

Gambar 1. Bagan Metode Alur Pengabdian

Sesi selanjutnya merupakan membuat agenda pelatihan dan membuat susunan panitia salah satunya yaitu menentukan tim tutor. Dilanjutkan dengan membuat modul Microsoft Word Serta Excel sekaligus membuat kuesioner untuk memperkirakan tanggapan dari partisipan terkait pelatihan ini sebagai bahan evaluasi. 
1. Tabel 1. Daftar Uraian Pelatihan

\begin{tabular}{|c|l|l|}
\hline \multirow{2}{*}{ NO } & \multicolumn{2}{|c|}{ MATERI } \\
\cline { 2 - 3 } & \multicolumn{1}{|c|}{ PERTAMA } & \multicolumn{1}{c|}{ KE DUA } \\
\hline 1 & Penegnalan MS Word & $\begin{array}{l}\text { Penyimpanan Dokumen Hardfile pada lemari } \\
\text { penyimpanan }\end{array}$ \\
\hline 2 & Pengenalan MS Excel \\
\hline 3 & $\begin{array}{l}\text { Membuat Merger } \\
\text { Surat }\end{array}$ & Penyimpanan Dokumen softfile secara digital \\
\hline 4 & $\begin{array}{l}\text { Membuat Format } \\
\text { Surat menyurat }\end{array}$ & \\
\hline
\end{tabular}

Peserta pelatihan MS Word, MS Excel dan administrasi perkantoran, para peserta merasa sangat terbantu dalam memahami Setelah pelatihan MS Word, MS Excel dan administrasi perkantoran ini, peserta pelatihan mempunyai kemampuan dalam mempersiapkan dan membuat dokumen secara mandiri, serta pengarsipan surat secara baik.

\section{Hasil}

Pelaksanaan pelatihan administrasi perkantoran adalah proses pelaksanaan administrasi yang meliputi urusan ketatausahaan, urusan pengarsipan. urusan penyimpanan dun sebagainya. Peranan staf tata usaha dan guru dalam setiap organisasi/lembaga sangat penting karena tanpa adanya keduanya maka kegiatan suatu organisasi/lembaga tidak akan berjalan atau dengan kata lain bahwa proses penyelenggaraan administrasi perkantoran tidak dapat dilaksanakan (Mambo, 2015).

Pelatihan ini dilakukan oleh 8 tutor 7 mahasiswa dibantu oleh 1 orang Dosen Peeserta adalah 20 orang yang terdiri dari Pria 9 siswa, Wanita 8 siswi. tata usaha 3 orang. Pelatihan ini dicoba memakai laptop serta LCD secara bergantian dengan materi yang berbeda sepanjang hari yang dilaksanakan pada 28-29 April 2020. Totalitas rangkaian pelatihan ini berjalan dengan lancar serta tertib dengan semangat yang tinggi. Partisipai siswa/i yang sangat baik dengan keinginan yang besar berupaya dapat mengoperasikan Microsoft Word serta Excel dilihat dari antusiasme partisipan buat ingin belajar (Warjiyono \& Ery Suryanti, 2021). 
Dari hasil penelitian diketahui dengan tampilan tabel di bawah ini :

Tabel 2. Hasil evaluasi pelatihan Microsoft Word

\begin{tabular}{|c|c|c|c|c|c|c|c|}
\hline \multirow{2}{*}{ No } & \multirow{2}{*}{ Uaraian Pertanyaan } & \multicolumn{3}{|c|}{ Sebelum Pelatihan } & \multicolumn{3}{|c|}{ Sesudah Pelatihan } \\
\hline & & $\mathrm{B}$ & C & $K$ & $\mathrm{~B}$ & C & K \\
\hline 1 & $\begin{array}{l}\text { Apakah sudah bisa } \\
\text { membuat surat dan kop } \\
\text { surat? }\end{array}$ & & 3 & 17 & 13 & 6 & 1 \\
\hline 2 & $\begin{array}{l}\text { Apakah sudah bisa } \\
\text { menyisipkan dan seting } \\
\text { gambar \& shape? }\end{array}$ & & 3 & 17 & 10 & 7 & 3 \\
\hline 3 & $\begin{array}{l}\text { Apakah sudah bisa } \\
\text { menggunakan perintah } \\
\text { dasar seperti mengubah } \\
\text { jenis huruf, warna } \\
\text { huruf, ukuran huruf? }\end{array}$ & & 7 & 13 & 16 & 3 & 1 \\
\hline 4 & $\begin{array}{l}\text { Apakah sudah bisa } \\
\text { setting margin, ukuran } \\
\text { kertas dan layout? }\end{array}$ & & 6 & 14 & 17 & 3 & \\
\hline 5 & $\begin{array}{l}\text { Apakah sudah bisa } \\
\text { setting paragraph dan } \\
\text { spasi? }\end{array}$ & & 3 & 17 & 16 & 3 & 1 \\
\hline 6 & $\begin{array}{l}\text { Apakah sudah bisa } \\
\text { membuat header \& } \\
\text { Footer? }\end{array}$ & & 2 & 18 & 15 & 3 & 2 \\
\hline 7 & $\begin{array}{l}\text { Apakah sudah bisa } \\
\text { membuat halaman } \\
\text { dokumen? }\end{array}$ & & 4 & 16 & 10 & 7 & 3 \\
\hline 8 & $\begin{array}{l}\text { Apakah sudah bisa } \\
\text { membuat tabel? }\end{array}$ & & 3 & 17 & 10 & 6 & 4 \\
\hline 9 & $\begin{array}{l}\text { Apakah sudah bisa } \\
\text { membuat mail merge? }\end{array}$ & & & 20 & 10 & 7 & 3 \\
\hline 10 & $\begin{array}{l}\text { Apakah sudah bisa } \\
\text { mencetak dokumen? }\end{array}$ & & 7 & 13 & 13 & 5 & 2 \\
\hline
\end{tabular}

a. Tabel. 2 membuktikan bahwa 20 orang peserta sebelum dicoba pelatihan Microsoft Word 75\% menerangkan belum mampu mengoperasikan Microsoft Word. Setelah dilakukan pelatihan sehingga 
hasilnya yaitu $60 \%$ baik (B), $25 \%$ cukup (C) dan $10 \%$ kurang (K). Setidaknya banyak menguasai pada pengoperasian perintah dasar Microsoft Word seperti mengubah tipe huruf, warna huruf, ukuran huruf, setting paragraph dan spasi, membuat halaman dokumen dan mencetak dokumen. Sedangkan yang masih kurang (K) adalah pada pengoperasian setting margin, ukuran kertas serta layout, setting paragraph dan spasi, sementara penguasaan membuat tabel dan membuat mail merge masih 50\%.

Tabel 3. Hasil evaluasi pelatihan Microsoft Excel

\begin{tabular}{|c|c|c|c|c|c|c|c|}
\hline \multirow{2}{*}{ No } & \multirow{2}{*}{ Uaraian Pertanyaan } & \multicolumn{3}{|c|}{ Sebelum Pelatihan } & \multicolumn{3}{|c|}{ Sesudah Pelatihan } \\
\hline & & B & $C$ & $K$ & B & C & K \\
\hline 1 & $\begin{array}{l}\text { Apakah sudahpernah } \\
\text { membuat tabel di } \\
\text { Microsoft Excel? }\end{array}$ & & 1 & 19 & 15 & 5 & \\
\hline 2 & $\begin{array}{l}\text { Apakah bisa membuat } \\
\text { penomoran Microsoft } \\
\text { Excel secara otomatis }\end{array}$ & & 5 & 15 & 20 & & \\
\hline 3 & $\begin{array}{l}\text { Apakah sudah bisa } \\
\text { bekerja dan mengatur } \\
\text { worksheet \& } \\
\text { workbook? }\end{array}$ & & 2 & 18 & 15 & 5 & \\
\hline 4 & $\begin{array}{l}\text { Apakah sudah bisa } \\
\text { menggunakan fungsi } \\
\text { matematika pada } \\
\text { Microsoft Excel? }\end{array}$ & & & 20 & 10 & 6 & 4 \\
\hline 5 & $\begin{array}{l}\text { Apakah sudah bisa } \\
\text { menggunakan perintah } \\
\text { dasar seperti } \\
\text { mengubah jenis huruf, } \\
\text { warna huruf, ukuran } \\
\text { huruf dan merubah } \\
\text { huruf besar dan kecil? }\end{array}$ & & 2 & 18 & 15 & 3 & 2 \\
\hline 6 & $\begin{array}{l}\text { Apakah pernah bekerja } \\
\text { dua jendela pada } \\
\text { Microsoft Excel? }\end{array}$ & & & 20 & 15 & 3 & 2 \\
\hline 7 & $\begin{array}{l}\text { Apakah sudah bisa } \\
\text { mengatur tampilan } \\
\text { ukuran kertas sebelum }\end{array}$ & & 3 & 17 & 16 & 2 & 2 \\
\hline
\end{tabular}




\begin{tabular}{|c|c|c|c|c|c|c|}
\hline & mencetak print out? & & & & & \\
\hline 8 & $\begin{array}{l}\text { Apakah sudah bisa } \\
\text { menggunakan preview } \\
\text { dan print? }\end{array}$ & 5 & 15 & 16 & 3 & 1 \\
\hline 9 & $\begin{array}{l}\text { Apakah sudah bisa } \\
\text { memahami merubah } \\
\text { nama pada lembar } \\
\text { kerja (work sheet)? }\end{array}$ & 3 & 17 & 13 & 5 & 2 \\
\hline 10 & $\begin{array}{l}\text { Apakah sudah bisa } \\
\text { memformat Microsoft } \\
\text { Excel ke pdf }\end{array}$ & & 20 & 10 & 6 & 4 \\
\hline
\end{tabular}

b. Tabel 3, menunjukan bahwa 20 siswa/i dan TU peserta sebelum dilakukan pelatihan Microsoft Excel 15\% cukup (C) dan 85\% kurang (K) dalam mengoperasikan Microsoft Excel. Setelah dilakukan pelatihan maka hasilnya adalah $65 \%$ baik (B), $25 \%$ cukup (C) dan 10\% kurang (K). Paling banyak mengusai di preview dan mencetak dokumen. Sedangkan yang masih kurang (K) adalah memahami rumus matematika dan funsi, serta belum memahami mengatur dokumen ke format pdf.

Tabel 4. Hasil evaluasi pelatihan Penyimpanan Dokumen di googe drive

\begin{tabular}{|c|l|c|c|c|c|c|c|}
\hline \multirow{2}{*}{ No } & \multirow{2}{*}{1} & \multicolumn{3}{|c|}{ Sebelum Pelatihan } & \multicolumn{3}{|c|}{ Sesudah Pelatihan } \\
\cline { 2 - 7 } 1 & $\begin{array}{l}\text { Apakah sudah bisa } \\
\text { membuat folder } \\
\text { penyimpanan? }\end{array}$ & B & C & K & B & C & K \\
\hline 2 & $\begin{array}{l}\text { Apakah bisa } \\
\text { membedakan antara } \\
\text { file dan folder }\end{array}$ & 5 & 18 & 13 & 5 & 2 \\
\hline 3 & $\begin{array}{l}\text { Apakah sudah } \\
\text { memahami google } \\
\text { drive? }\end{array}$ & $\begin{array}{l}\text { Apakah sudah } \\
\text { menggunakan google } \\
\text { drive }\end{array}$ & 20 & 10 & 7 & 3 \\
\hline
\end{tabular}




\begin{tabular}{|c|c|c|c|c|c|}
\hline 5 & $\begin{array}{l}\text { Apakah sudah bisa } \\
\text { membedakan google } \\
\text { drive sendiri dan } \\
\text { bersama? }\end{array}$ & 20 & 7 & 7 & 6 \\
\hline 6 & $\begin{array}{l}\text { Apakah sudah bisa } \\
\text { menggunakan } \\
\text { penyimpanan pada } \\
\text { google drive? }\end{array}$ & 20 & 8 & 8 & 4 \\
\hline 7 & $\begin{array}{l}\text { Apakah sudah pernah } \\
\text { update dokumen dari } \\
\text { pc ke google drive }\end{array}$ & 20 & 8 & 7 & 4 \\
\hline 8 & $\begin{array}{l}\text { Apakah sudah bisa } \\
\text { membuka dokumen di } \\
\text { google drive dengan } \\
\text { smartphone/android? }\end{array}$ & 20 & 7 & 7 & 6 \\
\hline 9 & $\begin{array}{l}\text { Apakah sudah bisa } \\
\text { menpapilkan dokumen } \\
\text { pada pencarian di } \\
\text { google drive? }\end{array}$ & 20 & 8 & 7 & 5 \\
\hline 10 & $\begin{array}{l}\text { Apakah semua } \\
\text { dokumen tersimpan di } \\
\text { google drive }\end{array}$ & 20 & 8 & 8 & 3 \\
\hline
\end{tabular}

c. Tabel 4, menunjukan bahwa 20 Siswa/i dan TU peserta sebelum dilakukan pelatihan Penyimpanan File di google drivel 7\% cukup (C) dan 93\% kurang (K) bisa melakukan penyimpanan file dokumen di google drive. Setelah dilakukan pelatihan maka hasilnya adalah $65 \%$ baik (B), 20\% cukup (C) dan 15\% kurang (K).

Paling banyak setidaknya sudah bisa menata penyimpanan file dokumen di google drive. Sedangkan yang masih kurang (K) adalah membuat drive bersama dan mengupdate file dokumen di google drive 


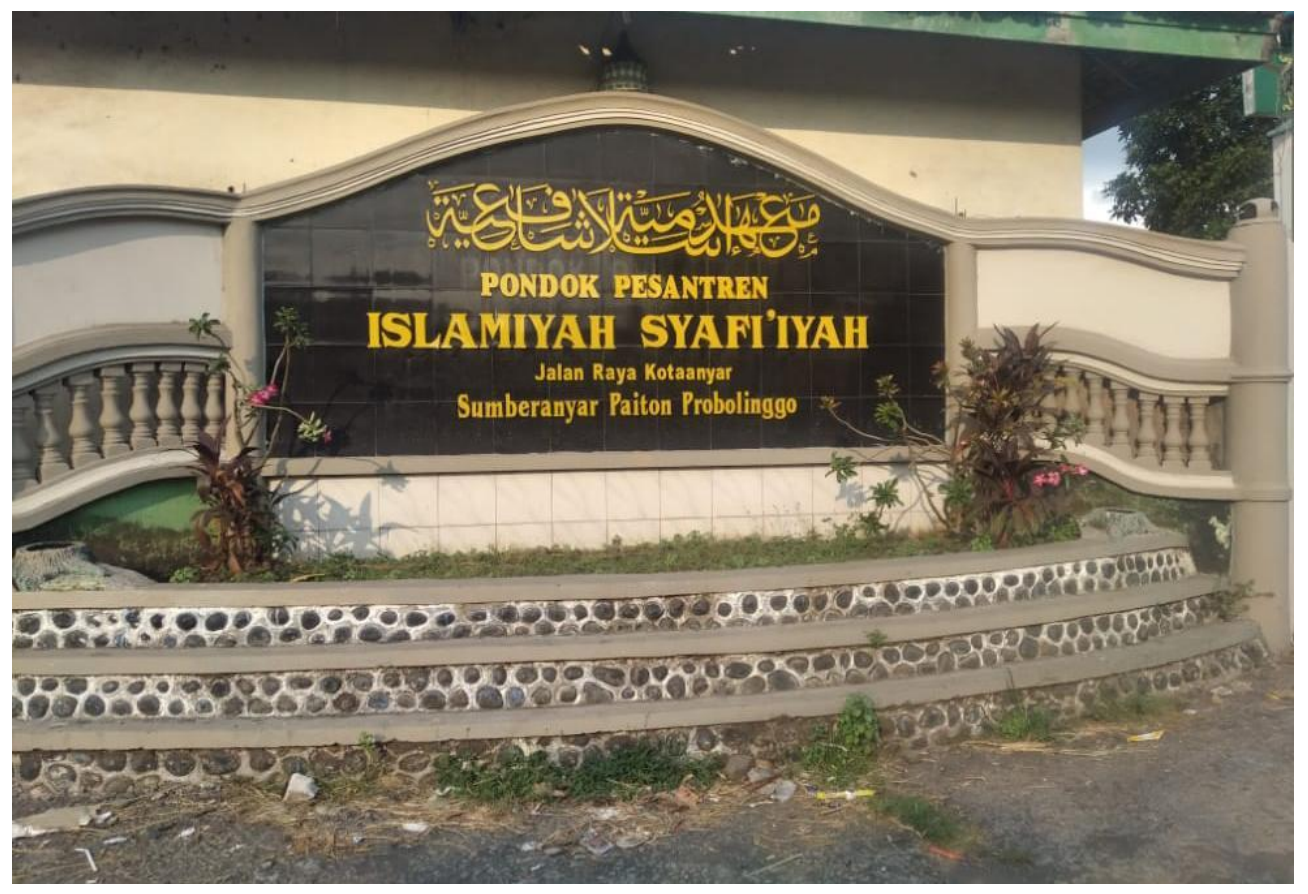

Gambar 1. Lokasi Pengabdian Masyarakat

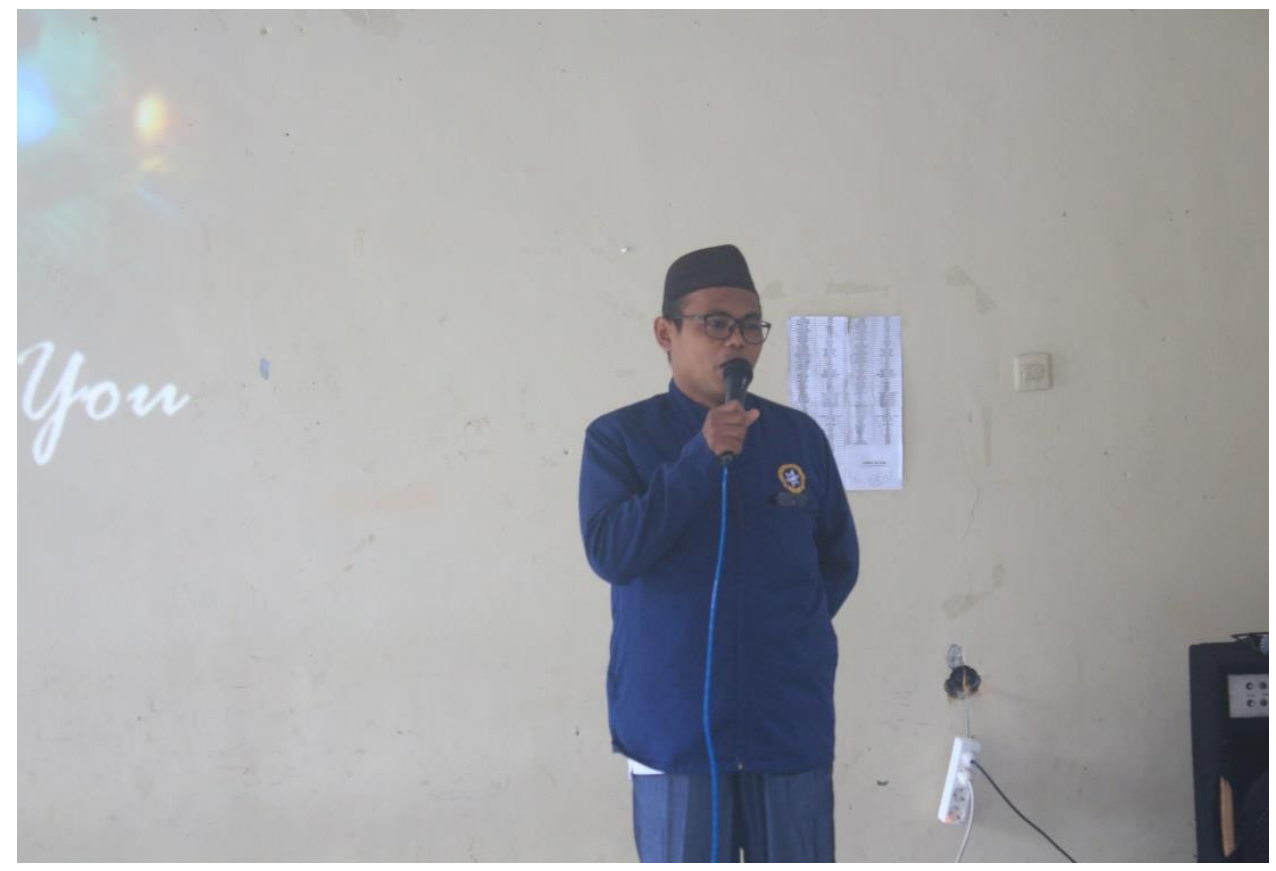

Gambar 2. Pengantar Pelaksanaan pelatihan 


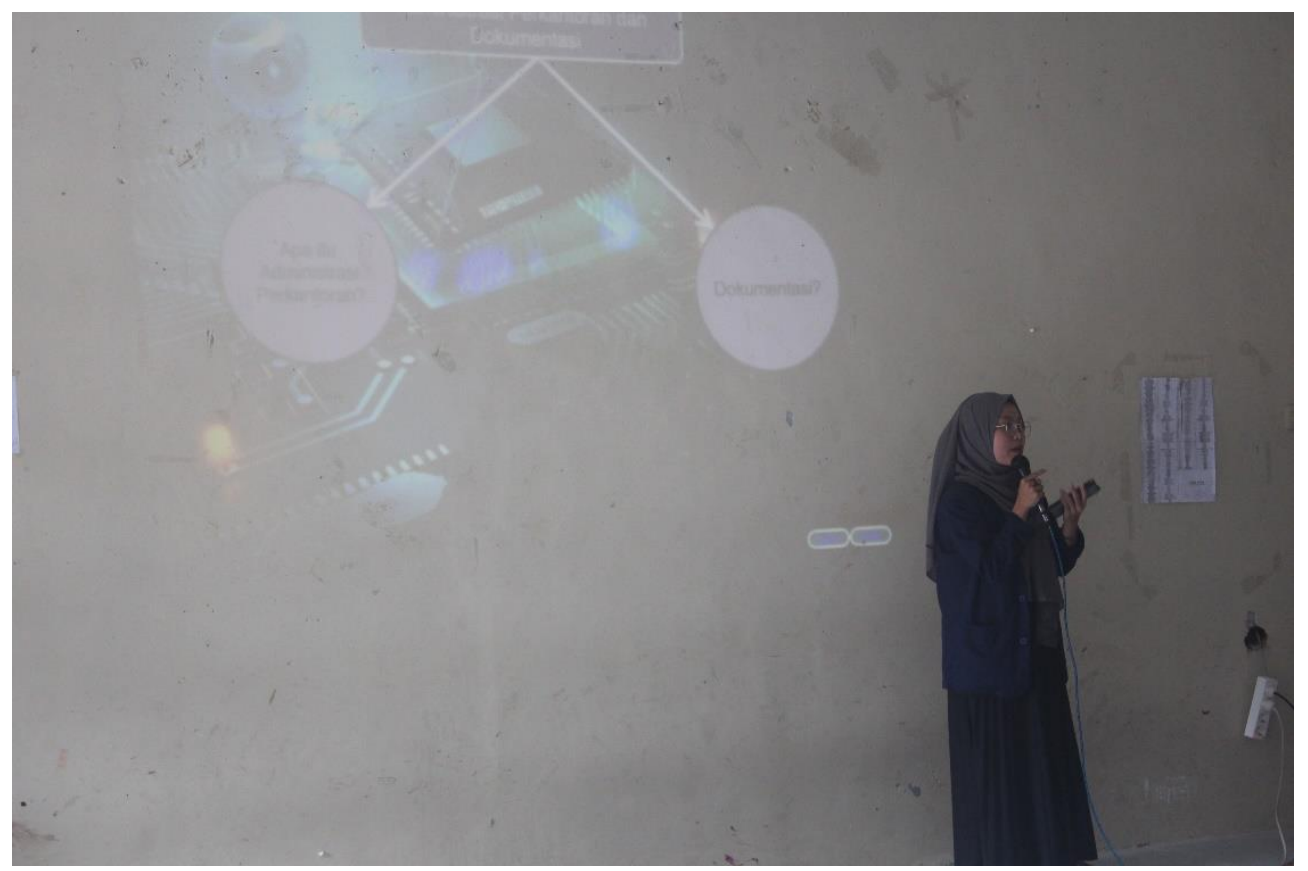

Gambar 3. Pelaksanaan pelatihan Word \& Excel 2013

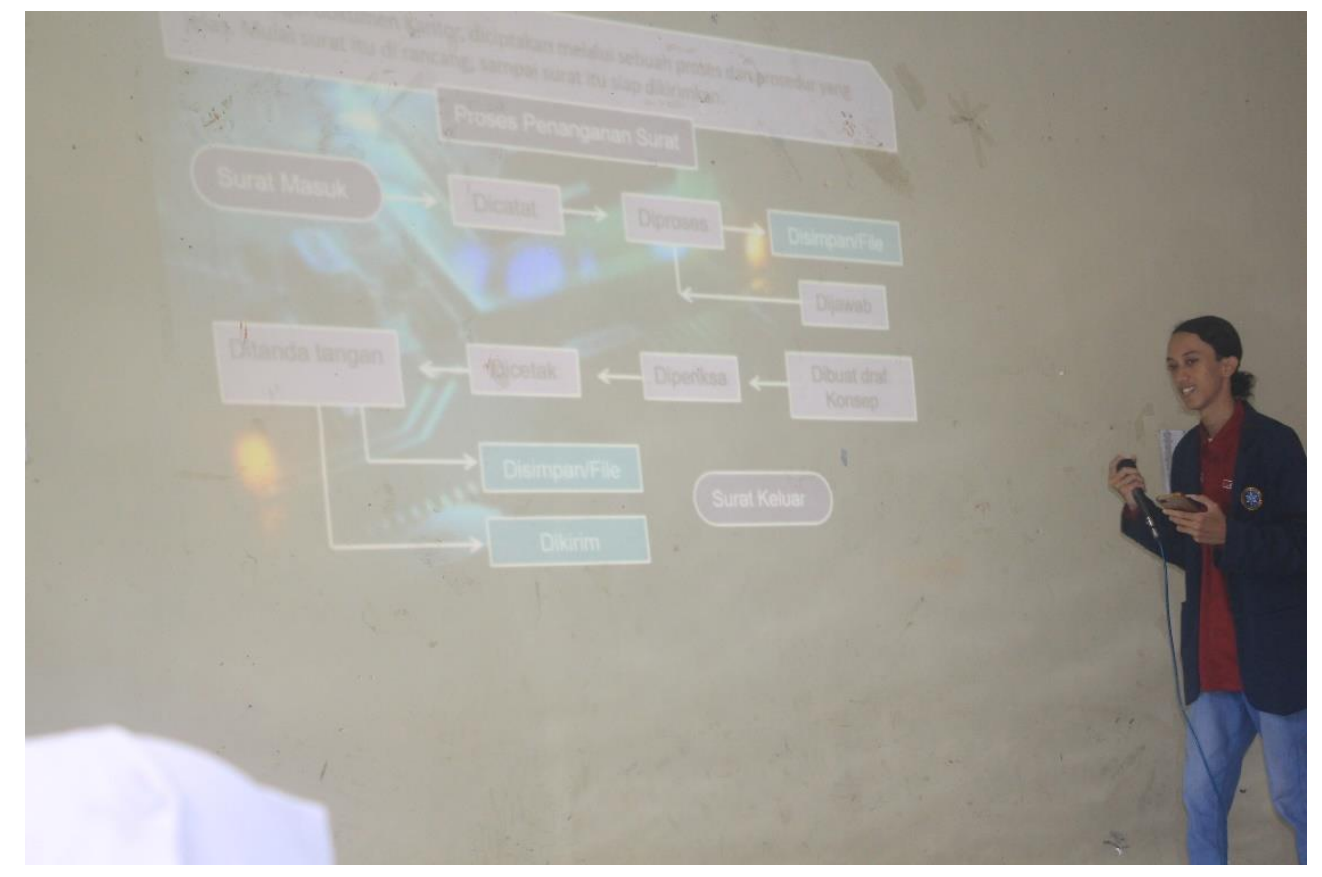

Gambar 4. Pelaksanaan pelatihan Dukumentasi Surat-menyurat 


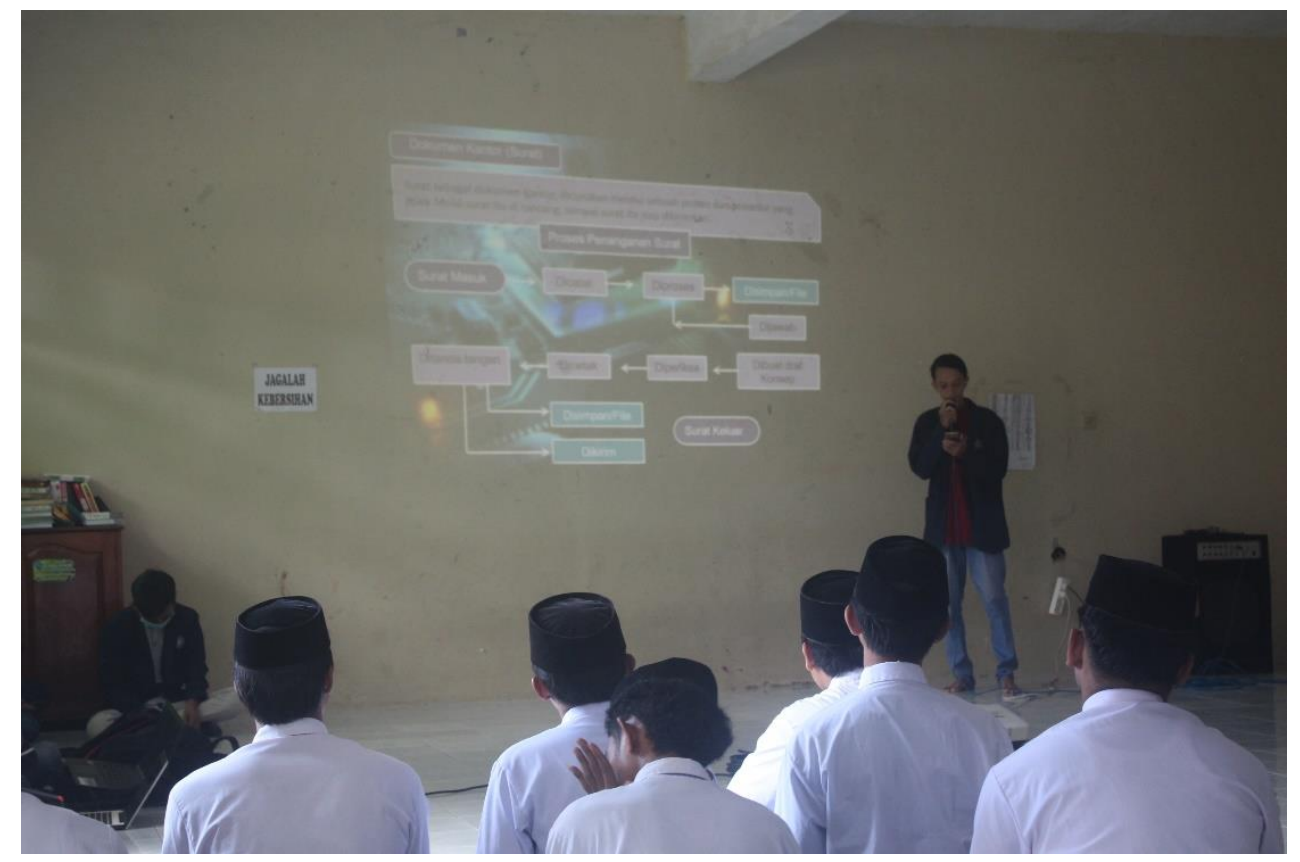

Gambar 5. Pelaksanaan pelatihan mail merge pada Surat-menyurat

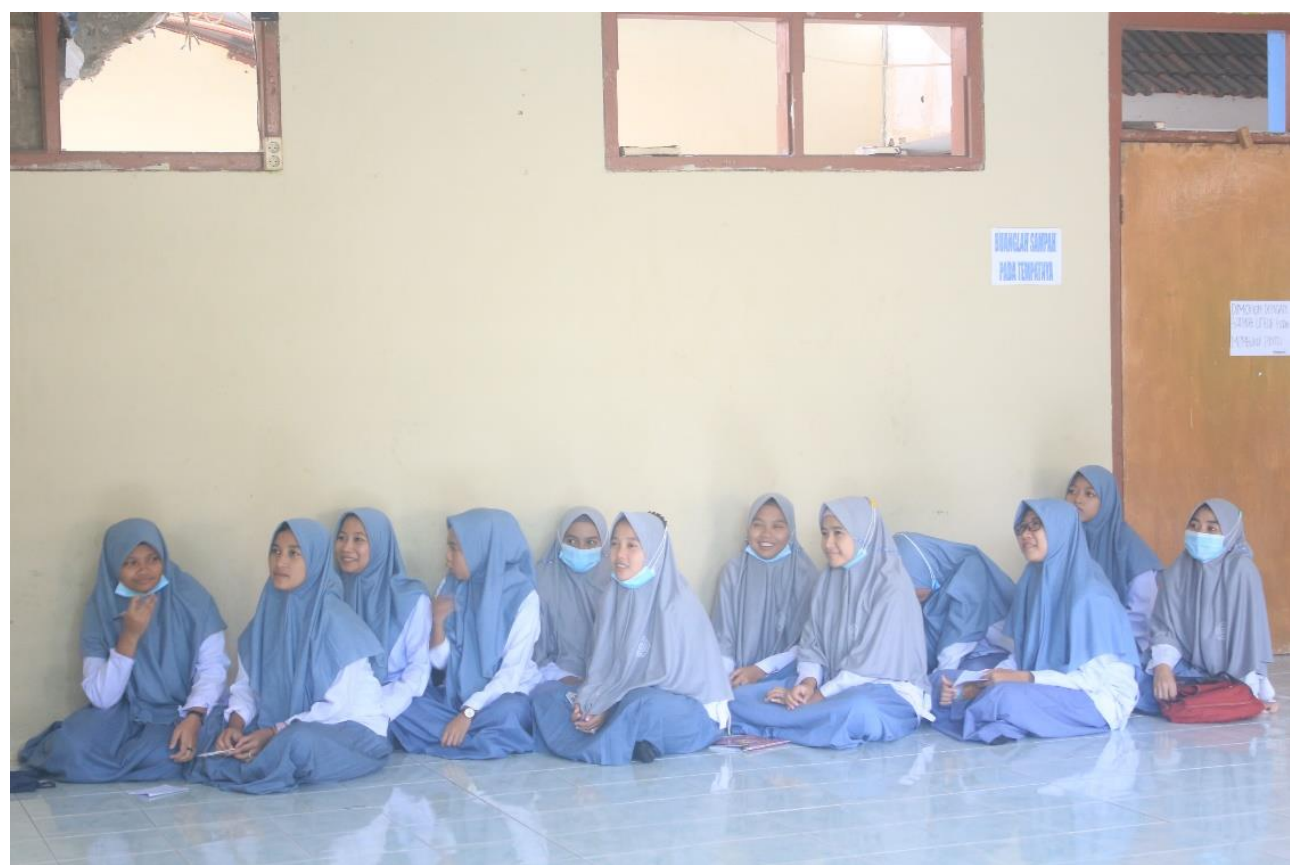

Gambar 6. Peserta pelatihan siswi kelas akhir 


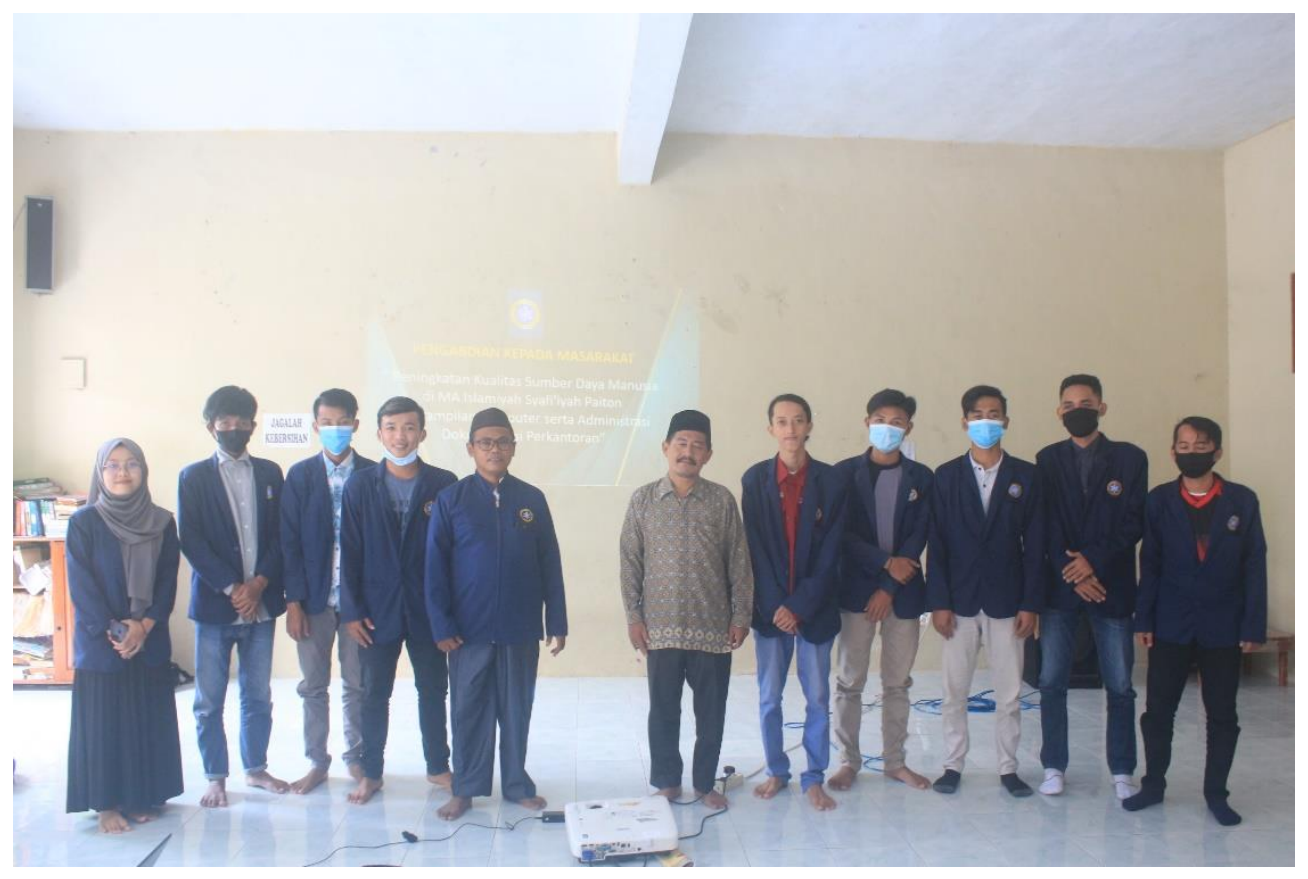

Gambar 7. Peserta Pengabdian dan Kepala Madrasah MIAS

\section{Kesimpulan}

Adapun kesimpulan dari pelaksanaan pengabdian masyarakat berbentuk pelatihan Microsoft Word dan Excel 2013 serta Dokumentasi di Madrasah Aliyah Islamiyah Syafi'iyah Sumberanyar Paiton Probolinggo sebagai berikut:

1. Pelaksanaan pengabdian masyarakat berupa pelatihan untuk Madrasah Aliyah Islamiyah Syafi'iyah Sumberanyar Paiton Probolinggol, sudah dilaksanakan serta berjalan dengan baik dan lancar walaupun suasana pedemi peserta masih antusias

2. Pelatihan Microsoft Word dan Excel 2013 serta Dokumentasi di Madrasah Aliyah Islamiyah Syafi'iyah Sumberanyar Paiton Probolinggo efek yang diraskan sekarang tertibananya skill serta meningkatan sdm pada siswa/i serta TU di Madrasah Aliyah Islamiyah Syafi'iyah Sumberanyar Paiton Probolinggo

3. Beberapa materi pelatihan yang dilaksanakan ada beberapa point pengarunya kurang dipahami oleh siswa/i dan TU Madrasah Aliyah Islamiyah Syafi'iyah Sumberanyar Paiton Probolinggo antara lain: 
a. Membuat surat secara masal dengan mail merge karena tidak terbiasa mengkobinasikan data surat dari Microsoft Wosrd dengan Microsoft Excel

b. Kesulitan menggunakan rumus matematika pada Microsoft Excel serta tidak paham funsi logika perhitungan dengan rumus-rumus yang ada.

c. Selanjutnya tidak strukturnya penyimpanan file dan folder sehingga kesulitan dalam pencarian menapilkan kembali dan tidak terbaiasa penyimpanan secara digital (Google Drive).

\section{Pengakuan}

Sebagai ucapan rasa Syukur atas terciptanya kerjasamanya pihak sekolah Madrasah Aliayah Islamiyah Syafi'iyah Sumberanyar Piton Probolinggo sehingga kegiatan pengabdian masyarakat ini berjalan lancar walau kurang masih kurang dari sempurna, utamanya Bapak Kepala Sekolah dan para dewan Guru Madrasah Aliayah Islamiyah Syafi'iyah Sumberanyar Piton Probolinggo.

Sedangkan saran dari pelatihan pengabdian masyarakat berupa pelatihan Microsoft Word Microsoft Excel 2013 serta Dokumentasi Madrasah Aliayah Islamiyah Syafi'iyah Sumberanyar Piton Probolinggo, perlunya diadakan pelatihan kembali dan pendampingan khususnya mater-materi yang tidak mudah dipahami agar supaya dalam pengoperasian Microsoft Word Microsoft Excel 2013 serta Dokumentasi menjadi lebih baik sehingga bisa membantu kelancaran serta meningkatkan SDM serta pelayanan 


\section{Daftar Pustaka}

Aribowo, D., \& Endi Permat, R. (2017). PENINGKATAN KOMPETENSI INFORMATION TECHNOLOGY (IT) BAGI APARATUR PEMERINTAH DAN MASYARAKAT MELALUI ICT-TRAINING DI KELURAHAN PABEAN KECAMATAN PURWAKARTA KOTA CILEGON. jurnal.untirta.

Arsana, I. N., \& Dewa Ayu Putri Wulandari. (n.d.). PELATIHAN DASAR KOMPUTER DAN TEKNOLOGI INFORMASI BAGI PERANGKAT DESA KUKUH. 2021.

Mambo, R. (2015). PENTINGNYA PENINGKATAN SUMBERDAYA MANUSIA DALAM PENYELENGGARAAN ADMINISTRASI PERKANTORAN PADA KANTOR SEKRETARIAT DAERAH KABUPATEN KEPULAUAN SANGIHE.

Permatasari, C. L., \& lis Nawati. (2018). Kompetensi Sumber Daya Manusia Perkantoran Di Era Milenial.

Pradana, R., \& Dwi Achadiani. (2020). PELATIHAN PEMBUATAN SURAT LAMARAN KERJA MENGGUNAKAN MICROSOFT WORD PADA PKBM DHARMA PUTRA MANDIRI . JATTEC.

PRATAMA, S. (2019). ANALISA PENGARUH SUMBERDAYA MANUSIA, PRASARANA DAN LINGKUNGAN KERJA TERHADAP KINERJA STUDI PADA PEGAWAI UNIVERSITAS PEMBANGUNAN PANCA BUDI MEDAN. Jurnal Manajemen Tools.

Siagian, Y., \& Jeperson Hutahaean, Z. A. (Juli 2019). PELATIHAN APLIKASI MICROSOFT OFFICE 2010 DAN INTERNET UNTUK PARA SISWA DAN TUTOR PADA LEMBAGA KURSUS PENDIDIKAN (LKP) MANDIRI COMPUTER KABUPATEN ASAHAN SUMATERA UTARA . Jurdimas (Jurnal Pengabdian Kepada Masyarakat) Royal , 153 - 158.

Warjiyono, \& Ery Suryanti, R. F. (2021). Pelatihan Aplikasi Perkantoran Untuk Meningkatan Kualitas SDM Perangkat Desa Karangmangu. JURNAL ABDIMAS BSI.

Warjiyono, \& Ery Suryanti, R. F. (Februari 2021). Pelatihan Aplikasi Perkantoran Untuk Meningkatan Kualitas SDM Perangkat Desa Karangmangu. JURNAL ABDIMAS BSI, Vol. 4 No. 1, Hal. 156-163.

Yuliani, W. (2018). METODE PENELITIAN DESKRIPTIF KUALITATIF DALAM PERSPEKTIF BIMBINGAN DAN KONSELING. QUANTA. 